\title{
Barend Jacobus Engelbrecht - 'n Oorsig en waardering
}

\author{
JP Oberholzer
}

Op 31 Desember 1988 aanvaar prof dr BJ Engelbrecht emeritaat. Gebore 1 Augustus 1923 in die distrik Heidelberg, Transvaal, gematrikuleer in 1940 in die eerste klas aan die Volkskool, Heidelberg, gegradueer aan die Universiteit van Pretoria, BA (met lof) 1943, BD (met lof) 1946, en die Rijksuniversiteit van Groningen, Drs Theol (met lof) 1949, D Theol 1949, professor in en hoof van die Departement Sistematiese Teologie vanaf 1952, voltooi hy vanjaar 'n sewe en dertig jarige akademiese loopbaan en word hy daarmee die hoogleraar wat die langste diens in die Fakulteit Teologie (Afd A) aan die Universiteit van Pretoria gelewer het. In hierdie tydperk was hy bowendien dekaan vanaf 1970 tot 1987, senaatsverteenwoordiger in die Raad van die Universiteit vanaf 1972 tot 1987, lid van die Dissiplinêre Komitee (Studente) van die Universiteit vanaf 1972 tot 1987, lid van die Boukomitee, die Finansies- en Eiendomskomitee en die Senior Aanstellingskomitee oor lang tydperke. Hy is volle lid van die Suid-Afrikaanse Akademie vir Wetenskap en Kuns en lid van die Senaat van die Universiteit van die Noorde.

Wie met Ben Engelbrecht kennis gemaak het in sy studentetyd, het reeds toe oortuig geraak van sy fenomenale geheue, sy natuurlike aanleg om ingewikkelde sisteme en gedagtestrukture te begryp en in eenvoudige taal weer te gee en sy nugtere geestesbalans. Sy doktorale proefskrif, Die tydstruktuur in die gedagtekompleks Hegel-KierkegaardBarth, het getoon watter omvattende en deurdringende wetenskaplike arbeid van hom te wagte sou kon wees, en nou, na sewe en dertig jaar, blyk dit dat die verwagting nie beskaam is nie. Selfs net ' $n$ vlugtige blik deur die lys van publikasies sou dit kon bevestig, maar dan is nog buite rekening gelaat die talle ongepubliseerde voordragte en kerklike adviese wat hy in die loop van jare gelewer het, die leiding aan voor- en nagraadse studente, en die persoonlike gesprekke - gebeure wat steeds verrykend was. Dit spreek van 'n besondere teologiese wydte dat hy vanweë besondere omstandighede in die Fakulteit op 'n tyd doktorale leiding kon gee nie alleen in die Sistematiese Teologie nie, maar ook in Praktiese Teologie, Nuwe-Testamentiese Wetenskap en Godsdiens- en 
Sendingwetenskap. Op 'n bepaalde stadium het drie van sy kollegas in die Fakulteit onder sy promovendi getel. Belangriker as die hoeveelheid is die kwaliteit van die werk wat gelewer is. Elke wetenskaplike en populêr-wetenskaplike geskrif, elke voordrag en advies, elke gesprek was ' $n$ toonbeeld van fyn sistematiese denke, analities en sinteties, en 'n vermoë om te kommunikeer. Dit is die rede waarom ook sy stokperdjies wetenskaplike prestasies geword het. Hengel het vir hom beteken noukeurige studie van die habitat en lewensgewoontes van die visse en hulle natuurlike prooi, eiehandige vervaardiging van kunsaas, die ontwikkeling van suksesvolle hengeltegnieke, en die sistematiese beskrywing daarvan. Dieselfde geld van sy omgang met motors en van sy vertelkuns.

Ek herinner my goed sy optrede voor die Van der Hoff-reünie in 1950 oor die onderwerp "Eksistensiefilosofie en Teologie". Pas bevestig as predikant in die Nederduitsch Hervormde Gemeente Florida, was die jong geleerde besield met die Reformatoriese erfenis soos dit verwoord is deur Karl Barth en Emil Brunner. Sy kennismaking in Groningen met Van der Leeuw, Haitjema en Van Oyen het hom geprikkel tot intense studie van die geskrifte van die Reformatore self, en hy het Calvynkenner by uitnemendheid geword; maar voorop het steeds gebly die studie van die Heilige Skrif self. Hy het sy bedrewenheid in die Bybeltale en Eksegese nie verloor nie. Inteendeel, op eksegetiese gebied het hy op die hoogte gebly van die nuutste strominge en kan hy saampraat in die beste geselskap. Hoewel die teologie van Karl Barth hom steeds aangetrek het, sou dit waarskynlik verkeerd wees om hom te beskryf as 'n Barthiaan. Engelbrecht is 'n selfstandige verwoorder van die BybelsReformatoriese teologie, en het op eie unieke wyse die teologiese denkwêreld van die Nederduitsch Hervormde Kerk, en ook van SuidAfrika, bevrug en verryk. Wie die (lonende) moeite wil doen om kennis te neem van sy gepubliseerde werk, kom vanself tot dié gevolgtrekking, en sien ook hoedat sy teologiese insig en skerpte hom nie verlaat het waar hy op kulturele en maatskaplike terrein beweeg het nie.

Oor die jare 1964 tot 1983 het hy as lid en later vise-skriba van die Kommissie van die Algemene Kerkvergadering 'n groot aandeel gehad in die besluitneming en regering van die Nederduitsch Hervormde Kerk, maar ook daarvoor en daarna het hy deur middel van grondige adviese oor 'n wye verskeidenheid van sake die kerk gedien. Sy prediking was steeds dié van die gelowige teoloog wat die evangelie selfs vir die kleinste kind hoorbaar gemak het. As lid en soms as voorsitter van verskillende kerklike liggame het hy leiding geneem en 
deel gehad aan belangrike projekte, waaronder die nuwe Gesangebundel en die nuwe vertaling en versorging van die Belydenis- en Liturgiese Geskrifte. Hy was vir agtien jaar 'n gewaardeerde deelnemer aan die gesprekke op die Tussenkerklike Kommissie en het vanweë sy insig en aard baie bygedra tot ' $n$ goeie verstandhouding tussen die kerke. Sy deelname aan die radioprogram Wat sê die Bybel? oor 'n tydperk van meer as veertien jaar het by ' $n$ groot luisteraarspubliek byval gevind en het sterk vormende invloed gehad ver buite die grense van sy eie kerk. Dit word die beste beskryf deur 'n uitspraak van iemand buite die Nederduitsch Hervormde Kerk: "die hele Suid-Afrika het vir prof Ben lief".

By hierdie laaste woorde wil die Redaksie aansluit: Hier is ' $n$ man wat sy gawes vrylik beskikbaar gestel het oor 'n wye veld, en wat in nederige diens, teologiese diepte en eenvoud ' $n$ warme en egte mens gebly het. Ons wens hom 'n geseënde ampsrus toe.

\section{TOEKENNINGS AAN PROF BJ ENGELBRECHT}

Prof Engelbrecht het verskeie toekennings ontvang. In 1986 ken die Kuratorium vir die Teologiese Opleiding aan hom die HCM Fourie Erepenning toe vir bevordering van die Bybels-Reformatoriese Teologie in Suid-Afrika. Hy ontvang ook etlike gedenkpennings: by geleentheid van die 50ste bestaansjaarviering van die Fakulteit 1967, die publikasie van die Nuwe Afrikaanse Psalm- en Gesangboek 1969 en by uittrede uit sy sewentien jarige dekaanskap 1987. Die Van der Hoff Teologiese Vereniging het in 1982 'n goue penning aan hom oorhandig uit erkentlikheid vir sy besondere teologiese bydrae. Ook sy stokperdjie het erkenning meegebring: 'n goue medalje uit Swede vir 'n vis van rekord-grootte, 'n vergulde medalje van die Oos-Transvaalse dorp Nelspruit vir bevordering van die toerisme deur sy aandeel in die sport van kunsaashengel, en soos dit 'n akademikus-sportman pas, 'n silwer medalje van die Suid-Afrikaanse Hengelaarsunie vir sy navorsing en publikasies (twee boeke) oor hengelvisse en kunsaas. Ter erkenning van sy uitmuntende loopbaan as dosent het die Verteenwoordigende Studenteraad van die Universiteit van Pretoria hom in 1988 vereer met die Dux Docens toekenning.

\section{PUBLIKASIES}

Hoewel die onderstaande lys nie al die publikasies van Engelbrecht verteenwoordig nie, is dit die mees omvattende waartoe ek (JPO-Red) 
kon kom na 'n paar dae van intensiewe ondersoek. Die getal en verskeidenheid daarvan spreek vir hulleself.

\section{Boeke en Versamelings}

1. 1967. Die amp van die diaken. Krugersdorp: NHW Pers. (pp 43).

2. sj. Ver bo korale (1,4). Krugersdorp: NHW Pers. (pp 24).

3. sj. Die wet van God. Pretoria/Kaapstad: HAUM. (pp 81).

4. 1970. Woord en diens. Pretoria: HAUM. (2de druk, 1972). (pp 45).

5. sj. My besoek aan Nederland 1975. Pretoria: Stensil - UP. (pp 124 plus bylaes).

6. 1978. Teologie in die kerk. Pretoria: HAUM. (pp 294).

7. 1979. Temas rondom die Reformasie. Pretoria: HAUM. (pp 150).

8. 1980. God, die Heilige Gees. Pretoria: HAUM. (pp 173).

9. 1981. Vrae en antwoorde uit die Bybel. Pretoria: HAUM. (pp 127).

10. 1982. Versamelde opstelle. Pretoria: Stensil-UP. 4 dele. Deel I (pp 127); Deel II (pp 131); Deel III (pp 122); Deel IV (pp 133).

\section{In Hervormde Teologiese Studies}

1. Die betekenis van die begrip "Vrees-van-die-Here" in Spreuke, Job en Prediker. Jaargang 7, pp 191-223.

2. Prof dr Gerhardus van der Leeuw. Jaargang 8, pp 1-7.

3. Das Tragische und der Mensch. Jaargang 8, pp 176-179.

4. Preek gehou by die kerklike ampsaanvaarding as hoogleraar, Sondag 24 Februarie 1952. Jaargang 8, pp 192-195.

5. Professor dr PJ Muller as dogmatikus. Jaargang 9, pp 271-282.

6. Die plek van sang en musiek in die protestantse erediens. Jaargang 10, pp 155-167.

7. Die praktiese sy van die prediking. Jaargang 12 , pp 11-20.

8. 'n Ernstige worsteling om 'n werklike geloofsetiek: Bespreking van Hendrik van Oyen, Evangelische Ethik I. Jaargang 13, pp 8-19.

9. Die teologiese hoofgedagtes in Kierkegaard se stryd teen die Hegelse sisteem. Jaargang 15, pp 66-87.

10. Opmerkings oor die moontlike hersiening van ons kerk se liturgiese geskrifte. Jaargang 16, pp 41-54.

11. Die praesentia realis en die protestantse erediens. Jaargang 16, pp 278-287.

12. Enkele dogmatiese opmerkings oor die kerklike leer aangaande die Triniteit. Jaargang 19, pp 138-189.

13. Vyftig jaar Dogmatiek - 'n huldeblyk aan Karl Barth. Jaargang 22, Aflewering 4, pp $62-78$.

14. Hedendaagse krisispunte in die Teologie. Jaargang 23, Aflewering $1 \& 2$, pp 5-23 (ook in Standpunte, Jaargang 20, No 6, pp 34-48).

15. "Persoonlike vryheid" teologies gesien. Jaargang 24, pp 70-89.

16. Die antwoord en taak van die kerk ten opsigte van sekularisasie. Jaargang $24, p p$ 142-154.

17. Genade en skoonheid. Jaargang 26, pp 29-33.

18. Die struktuur van die versoening volgens Rom $5,10 \mathrm{vv} ; 2$ Kor $5,18 \mathrm{vv}$; Efes 2, $11 \mathrm{vv}$ en Kol 1, 19 vv. Studia Theologica Varia SPJJ van Rensburg dedicata, pp 19-25.

19. Opmerkings rondom die basiese probleem van die Teologiese Etiek. Jaargang 34, Aflewering 3, pp 13-23.

20. Nuwere ontwikkelinge op die gebied van die Sistematiese Teologie. Jaargang 34, Aflewering 4, pp 45-69. 
21. Calvin and the Corpus Christianum. Jaargang 35, Aflewering $1 \& 2$, pp 11-21.

22. Die werk van die Heilige Gees. Jaargang 35, Aflewering $2 \& 4$, pp 6-18.

23. Wyle prof JI de Wet. Jaargang 40 (1984), pp 3-6.

24. Die boodskap van Romeine. Jaargang 40 (1984), pp 52-65.

25. Wat is die reg en die vryheid van die eksegeet? Jaargang 42 (1986), pp 485-501.

26. 'n Nuwe ekumeniese geloofsbelydenis? Jaargang 43 (1987), pp 72-85.

27. Teologie en ekologie. Jaargang 44 (1988), pp 23-38.

\section{In Ander Vaktydskrifte}

1. Liturgie in Suid-Afrika. Kerk en Eredienst. Jaargang IV, Nr 1 (1949), pp 12-21

2. Die Hollands-Afrikaanse Kerke in Suid-Afrika. Vox Theologica. Jaargang 19, Nr 5 (Mei 1949), pp 149-157.

3. Die diskontinue ontologie van Sóren Kierkegaard. Blad vir Bevordering van Filosofie in Suid-Afrika, 1951.

4. Sommige sinsverbande en samehange waarin die sprokie staan. Tydskrif vir Geesteswetenskappe, 1951.

5. Reaksie op vertraagde aksie. Standpunte. Jaargang 14/2 (1960), pp 33-47.

6. Vraag en antwoord - Die gesag van die predikant ten opsigte van die literatuur. Standpunte. Jaargang 18/1 (1964), pp 15-24.

7. Kapitalisme, Kommunisme, Liberalisme en die Kerk. Standpunte. Jaargang 18/5 (1965), pp 38-55.

8. Kerk en Ekumene. Standpunte. Jaargang 19/2 (1965), pp 6-15.

9. Enkele voorbeelde van "literêre verwysing" in die Nuwe Testament. Standpunte. Jaargang 24/2 (1970), pp 33-39.

10. Twee vroeë reaksies van Gereformeerde kant op Karl Barth. In die Skriflig. Jaargang 20, No 78 , Junie 1986, pp 2-9.

\section{In Bundels}

1. 1950. Die afbeeldbaarheid van Jesus Christus in die kuns, in Pro Regno Pro Sanctiario. (Feesbundel G v d Leeuw). Nijkerk: Callenbach, pp 177-192.

2. 1960. Die kommunisme en die godsdiens, in Kommunisme, Teorie en Praktyk. Pretoria: Van Schaik, pp 97-107.

3. 1964. The communist onslaught on the Church, in Christian Civilisation against Communism. Pretoria: Van Schaik, pp 27-76.

4. 1966. "Persoonlike Vryheid" teologies gesien, in Referate gelewer op die algemene vergadering, Pretoria: SA Akademie, pp 407-420.

5. 1970. Wat sê die Bybel? Pretoria: JP van der Walt. Deel I, pp 162; Deel II, 1972; pp 170. (Mede-outeur).

6. 1971. Ensiklopedie van die Wêreld, 10 dele. Stellenbosch: F Albertyn. Verskeie bydraes onder andere Nederduitsch Hervormde Kerk van Afrika, Kunsmatige inseminasie en proefbuisbabas, prof B Gemser, Ds MJ Goddefroy en prof PJ Muller, Sabbatswette.

7. 1973. Geloofsleer met ' $n$ werksindeling vir kategese. Pretoria: HAUM. (Medewerker). 7de herdruk 1977, pp 92.

8. 1975. Saaklike en literêre verwysing in die literatuur, in In en om die Letterkunde. Pretoria: HAUM, pp 14-24.

9. 1978. Ensiklopedie: Wëreldfokus, 16 dele. Ensiklopedie Afrikana. Verskeie bydraes onder andere: Nederduitsch Hervormde Kerk van Afrika (10 kolomme), die Nederduitsch Hervormde Sustersvereniging, die Ekumeniese Belydenisse, die Drie Formuliere van Enigheid. 
10. 1974. Die teologie van die hoop en die teologie van die revolusie, in Die Bybel en die moderne mens. Pretoria: SA Akademie, pp 39-51.

11. 1979. Die godsdiens van die Afrikaner, in PG Nel (red), Die kultuurontplooiing van die Afrikaner. Pretoria: HAUM, pp 48-63.

12. 1980. Afrikaanse Kultuuralmanak. Aucklandpark: FAK. Artikels oor Calvyn, SP Engelbrecht en Die eerste Kerkraad in die OVS, bevestig Februarie 1837.

13. 1982. Verslae van ooggetuies oor twee ryksdae, in Kerk in die wêreld. Feesbundel AD Pont, pp 72-79.

14. 1982. Hoekom dan in die kerk trou? in Venster op die huwelik. Potchefstroom: PU vir CHO, pp 91-98.

15. 1982. The problem of the concept of the "Personality" of the Holy Spirit according to Calvin, in Calvinus Reformator. Potchefstroom: PU vir CHO, pp 201-216.

16. 1986. Geloofsgenesing, in Onderskeiding van geeste. Potchefstroom: PU vir CHO, pp 105-115.

17. 1988. SA Biografiese Woordeboek. Artikel oor JAJH Greyvenstein in Suid-Afrikaanse Biografiese Woordeboek V, p 323.

\section{In Die Christelike Vrou}

1. Nuwe gebooie van Elizabeth Conradie, 1946.

2. Die taalwonder van Pinkster, Junie 1959.

3. Die ware feesvreugde van Kersfees, Desember 1959.

4. Etheria - Pelgrim en vrouejoernalis in die vroeg-Christelike kerk, 1961.

5. Die diakonale taak van die NHSV, 1961.

\section{In Die Hervormde Studenteblad}

1. 'n Kort geskiedenis van die Teologiese Vereniging Van der Hoff. Jaargang 1, Aflewering 1, pp 12-15.

2. Studie in blou. Jaargang 1, Aflewering 1, p 31. (Gedig).

3. Maria, die moeder van Jesus, 1947, p 6vv.

\section{In NHSV Jaarboek}

1. $1900-1950,1950$.

2. Dien die Here, 1950.

\section{In Van der Hoff Jaarblad}

1. Ek glo ... die wederopstanding van die vlees, 1966

2. 'n Woord vooraf (by die uittrede van prof ES Mulder), 1970.

3. Die eenheid van die kerk, 1972.

4. Die eenheid van die kerk, 1973.

5. Die probleem van wie mag aansit aan die Avondmaalstafel, 1973.

6. Die Cottesloe-beraad (Desember 1960), 1975.

7. Vyf-en-twintig jaar - 'n terugblik, 1976.

8. By die vyftigste verjaarsdag van die Teologiese Vereniging Van der Hoff. Gedenkalbum Van der Hoff Teologiese Vereniging 1924-1974. 


\section{In Die Hervormer se Nuusbrief}

1. Verdedigingsobligasies - Is die aansporingsbonusse geoorloof of nie? Nr 120, April 1977.

2. Proefbuisbabas. 15 Augustus 1978.

3. Ontslaan amptenare wat weier om landswet uit te voer. Desember 1981.

4. Wat God wil hê en wat die mense wil hê. 15 Desember 1981.

5. Nuwe wetgewing in verband met dienspligweiering. 15 Februarie 1983.

\section{In Ander tydskrifte}

1. Die drie bewegingswette van Newton. Trek 1944.

2. Die Woordleer in Johannes 1:1-14. Trek 1945.

\section{In Dagblaaie}

1. In Memoriam G van der Leeuw. Nederlandsche Post, Desember 1950.

2. The church concerned with the doctrine of Christ, not politics. The Star, 31 Oktober 1950.

3. Eine neue Ethik. Kirchenblatt für reformierte Schweiz. Basel, 17 Desember 1953.

4. Hemelvaart. Die Transvaler, 10 Mei 1956.

5. Aardsateliete en eskatologie. Die Huisgenoot, 1957.

6. Die Christelike toekomsverwagting en die toekoms van 'n volk. Geloftedag. No 5, 1957, pp 2-5.

7. "Want sonder my kan jy niks doen nie". Eerste Akademiese wydingsdiens van UP op Woensdagaand 20 Februarie 1957. Skakelblad, Jaargang 4, No 1, Maart 1957.

8. Rome in Suid-Afrika I-III. Die Gereformeerde Vroueblad, November 1961; Kersuitgawe 1961; Februarie 1962.

9. Wat word verwag van die Sondagskoolonderwyser? Weiding, Jaargang 10, Nr 3, 1962.

10. Die opstanding en hemelvaart van Jesus Christus. Weiding, 1963.

11. Pinksterfees. Weiding, 1963.

12. As die kerk eers sosiale instituut word ... Antikom, Deel 1, No 7, 1964.

13. Ek en my rytuig - 'n klein stukkie filosofie. Jeuguitgawe. Die Taalgenoot, Oktober 1969.

14. Kerk en sensuur. Hoofstad, 7 Februarie 1974.

15. Bijbelsche gerechtigheid als basis voor volkerenverhouding. Reformatorisch Dagblad, 1 Desember 1975.

16. Die charismatiese bewegings? HSV-blad van Stellenbosch, 1975.

17. 'n Gelofte aan God. Die Kerkbode, 13 Desember 1978.

18. Hulde aan Martin Luther. Die Transvaler, 10 Mei 1983.

19. Dienspligweiering op grond van gewetensbesware. Hoofstad, 27 Januarie 1983; Die Burger, 4 Maart 1983; Pretoria News, 7 Februarie 1983.

20. Genadedood? Die Transvaler, 24 September 1984

21. Gemengde huwelike. Die Transvaler, 19 April 1985.

In die Almanak van die Nederduitsch Hervormde Kerk van Afrika

1. Die Millenium of Duisendjarige Ryk. 1955, pp 49-56.

2. Geloftedag. 1959, pp 144-153. 
3. Kategismusprediking. 1960, pp 38-46.

4. Die Heidelbergse Kategismus. 1963, pp 43-50.

5. Die Bybelgenootskap van Suid-Afrika honderd-en-vyftig jaar oud - 'n Teologiese waardering. 1970, pp 11-16.

6. Die onderskeid tussen "onsigbare" en "sigbare" kerk en die betekenis daarvan ten opsigte van die eenheid van die kerk. 1978, pp 11-14.

7. Die vraag of (die) drie (susters) kerke met een en dieselfde belydenis binne een en dieselfde volk (met dieselfde taal, geskiedenis en kultuur) mag bestaan in die lig van die Bybels-Reformatoriese visie oor die eenheid van die kerk van Jesus Christus. 1978, pp 15-18.

8. Huldeblyk aan prof SP Engelbrecht. 1978, pp 41-42.

9. Die ontstaan en kanonisiteit van die Bybel. 1984, pp 11-18.

\section{In Die Hervormer}

1. Die Nederduitsch Hervormde Kerk van Afrika en die Nederlandsche Hervormde Kerk. November en Desember 1950.

2. Verslag in verband met die Protestantse Kongres te Pretoria op 31 Oktober 1950. Desember 1950.

3. Hoofmomente en hoofmotiewe van die Kerkhervorming. Oktober 1951.

4. Boodskap aan die kerk. Augustus 1951.

5. Doopskategese. 1957.

6. Offerbereidheid. 1958.

7. Die blydskap oor die diens van die Here in sy huis. Oktober 1958.

8. Die leer van John Knox oor die reg van opstand teen die burgerlike owerheid. Mei 1960.

9. Twee berigte oor die dood van Luther. September 1961.

10. Die Nederlandse Geloofsbelydenis vier eeue oud. November 1961.

11. Wat leer die Bybel ons van die hel? September 1962.

12. Enkele opmerkings by die vierde eeufees van die Heidelbergse Kategismus. Januarie 1963.

13. Die oudste berigte oor vrouediakens en hulle dienswerk in die kerk. November 1965 (ook in Die Christelike Vrou Februarie/Maart 1961).

14. Die Bybel in die volkstaal as vrug van die Hervorming. Oktober 1967.

15. Die Dordtse Leerreëls - 'n Lofsang tot eer van die soewereine, genadige God. November 1968.

16. Gesinsbeplanning vanuit teologiese gesigspunt belig. April 1969.

17. Weer eens die Dordtse Leerreëls. Mei 1969.

18. Geloftedag. Desember 1969.

19. Die Diens van Barmhartigheid as opdrag van God. Desember 1969.

20. Iets oor die probleme en taak van die Bybelvertaler. Augustus 1970.

21. Insake die amp in die Reformatoriese Teologie. April 1971.

22. Die Fakulteit en Van der Hoff. Christelik-Nasionaal as toonaard van die Teologiese Vereniging Van der Hoff en van die Opleiding van ons kerk.

23. By die afsterwe van prof dr ES Mulder. Julie 1974.

24. Ons en die Rooms-Katolisisme. Augustus, September en Oktober 1978.

25. Die Nuwe Gesangboek. Literêr suiwerder en teologies duideliker. Oktober 1978 (ook in Hoofstad 30 September 1978).

26. Die Nagmaal al meer verwaarloos. Mei 1979

27. Die betekenis van die Nagmaal. Junie 1979.

28. Die Nagmaal is sigbare Woord. Julie 1979.

29. Die Nagmaal is meer as net teken en herinnering. Augustus 1979. 
30. Kweekskool of Fakulteit - 'n belangrike beslissing. November 1980.

31. Predikant moet wetenskaplik met Bybel worstel. Desember 1980.

32. Bybel is enigste ware bron van kennis. Januarie 1981.

33. HP Wolmarans - 'n man van werklike groot invloed. Februarie 1981.

34. Hulpwetenskappe moet krities gebruik word. Maart 1981.

35. Is Teologie 'n wetenskap? I-III. April, Mei en Junie 1981.

36. Moet bidure gehou word? Jong Hervormer Junie 1981.

37. 'n Nuwe Ekumeniese Geloofsbelydenis, l-IIl. Julie, Augustus en September 1981.

38. Bekering is totale sinsverandering! (Aanhaling uit "God die Heilige Gees"). StudenteHervormer Oktober 1981.

39. Wanneer begin lewe? Julie 1982 (ook in Hoofstad 23 Julie 1982).

40. Briewe Proefbuisbevrugting: Regstelling van onduidelikhede in artikel. September 1982.

41. Agtergrond oor vroeë lede van teologiese fakulteit. Teologiese rubriek November 1982.

42. Hulde aan prof JI de Wet: 'n veelsydige beginselvaste kerkman. Teologiese rubriek Junie 1983.

43. Passiespel: Dié wyse van verkondiging is ongeoorloof. Julie en Augustus 1983.

44. Agtergrond oor vroeër lede van ons teologiese fakulteit. November 1983.

45. Die verband tussen doop en verbond mag nie deurgesny word nie. November 1983.

46. Belharbelydenis: 'n Valbyl, nie 'n gesprekspad. Oktober 1984.

47. Vryheid van keuse bring verantwoordelikheid mee. April 1985.

48. Karl Barth - Die dialektiese teoloog. Oktober 1986.

49. Karl Barth - 'n Herinnering en huldeblyk. September 1986.

50. Die Kerkhervorming vanuit 1987 gesien. Oktober 1987.

\section{Memoranda aan die Kommissie van die Algemene Kerkvergadering}

1. Tuguitoefening in verband met die ontheiliging van die Nagmaal. 1954.

2. Limited Atonement - Navraag DRC Ceylon. 1956.

3. Kerk en Israel I. 1959.

4. Die Gewetensklousule. 1959.

5. Kerk en Israel II. 1959.

6. Die hersiening van die diakensformulier. 1960.

7. Lykverbranding (mede-opsteller). 1961.

8. Artikel III van die Kerkwet en Artikels 5-8, Hoofstuk IV van die Bepalings. 1961.

9. Die kerklike belydenis en leer in verband met die artikel ["Ek glo] die wederopstanding van die vlees". 1961.

10. Wat is dwaalleer. 1962.

11. Sekere vrae in verband met die handoplegging. 1963.

12. Die doop. 1964.

13. Konseprapport aan Geref Kerk Nederland oor Artikel 36 NGB. 1964.

14. Die toelating van die vrou tot die kerklike ampte. 1964.

15. Simbole in die kerk. 1966.

16. Opsig, toesig en tug. 1966.

17. Die kruis in die kerk. 1966.

18. Naamsverandering van die kerk. 1975.

19. Stigting van 'n Instituut. 1975.

20. "Song of Hope". 1978.

21. Die betekenis van die Nagmaal vir die gelowige. 1979.

22. Enkele opmerkings oor die twee sakramente. 1980.

23. Die stadia van vernedering en verhoging. 1980. 
24. Egskeiding en die ampte. 1982.

25. Vroue as ouderlinge. 1982.

26. Die probleem van kunsmatige inseminasie by die mens. 1982 (en 1961).

\section{Vertalings in Afrikaans}

1967. Dr G Brillenburg Wurth, Christelike Sedeleer. Pretoria: JL van Schaik, pp 101. 